\title{
Measuring the Natural Rate of Interest
}

\author{
Thomas Laubach \\ John C. Williams \\ Board of Governors of the Federal Reserve System*
}

November 2001

\begin{abstract}
A key variable for the conduct of monetary policy is the natural rate of interest - the real interest rate consistent with output equaling potential and stable inflation. Economic theory implies that the natural rate of interest varies over time and depends on the trend growth rate of output. In this paper we apply the Kalman filter to jointly estimate the natural rate of interest, potential output, and its trend growth rate, and examine the empirical relationship between these estimated unobserved series. We find substantial variation in the natural rate of interest over the past four decades in the United States. Our natural rate estimates vary about one-for-one with changes in the trend growth rate. We show that policymakers' mismeasurement of the natural rate of interest can cause a significant deterioration in macroeconomic stabilization.

JEL classification: C32, E43, E52, O40.

Keywords: natural rate of interest, interest rate rules, Kalman filter, trend growth, potential output, equilibrium real interest rate.
\end{abstract}

\footnotetext{
*Washington, D.C. 20551, tlaubach@frb.gov, jwilliams@frb.gov. The views expressed herein are those of the authors and do not necessarily reflect those of the Board of Governors of the Federal Reserve System or its staff. We thank Adam Litwin for excellent research assistance. This research has benefitted from discussions with Antulio Bomfim, Bill English, Michael Kiley, Ed Nelson, John Roberts, Brian Sack, Bill Whitesell, and participants at sessions at the Econometric Society North American Summer Meeting and the International Conference of the Society of Computational Economics.
} 


\section{Introduction}

A key input into the conduct of monetary policy is a measure of the "neutral" stance of policy, against which one can gauge policy's stimulative or contractionary impetus. One such measure, especially prominent in regimes in which the central bank explicitly targets a monetary aggregate, is the growth rate of a monetary aggregate relative to some trend or target rate of growth. In the United States and many other countries, however, the short-term interest rate has become the primary policy instrument. In such regimes, the "equilibrium" or "natural" interest rate provides a metric for the stance of policy. For this purpose, it is useful to define the natural rate of interest to be the real short-term interest rate consistent with output converging to potential, where potential is the level of output consistent with stable inflation (Cf. Bomfim (1997)). In this formulation, the natural rate of interest, hereafter referred to as $r^{*}$, represents a medium-run real rate "anchor" for monetary policy and corresponds to the intercept term in feedback rules such as Taylor's (1993) Rule.

Economic theory implies that the natural rate of interest varies over time in response to shifts in preferences and technology. ${ }^{1}$ The relationship between $r^{*}$ and fundamentals is most clearly illustrated in the context of the standard optimal growth model. The optimality condition for saving yields a balanced growth condition relating the real interest rate, $r$, to preference and technology parameters:

$$
r=\frac{1}{\sigma} q+n+\theta
$$

where $\sigma$ denotes the intertemporal elasticity of substitution in consumption, $n$ is the rate of population growth, $q$ is the rate of labor-augmenting technological change, and $\theta$ is the rate of time preference. ${ }^{2}$ This finding that the real interest rate is positively related to the rates of trend growth and time preference, holding other factors fixed, holds in a wide

\footnotetext{
${ }^{1}$ If not for its time variation, estimation of the natural rate would be relatively straightforward. One simple approach is to take the sample mean over a relatively long period when inflation shows no upward or downward trend (Cf. Reifschneider and Williams (2000)). This method yields an estimate of $r^{*}$ of about 3 percent. Alternatively, one can derive an estimate of $r^{*}$ using an estimated macro model with fixed parameters (Cf. Taylor and Williams (1993), Orphanides and Wieland (1998), and Rudebusch (2001)).

${ }^{2}$ For this example, we assume CRRA preferences and that the utility of each future generation is weighted equally irrespective of size; if, instead, the utility of each generation is weighted according to its size, we have $r=\frac{1}{\sigma} q+\theta$.
} 
variety of models. ${ }^{3}$ In light of the evidence of substantial shifts in the trend growth rate in the United States and other countries over the past several decades (Cf. Maddison (1995), Oliner and Sichel (2000), Roberts (2001)), the assumption of a constant natural rate of interest appears untenable. Moreover, changes in other factors such as fiscal policy factors may induce persistent changes in the natural rate of interest over time.

Our definition of the natural rate is closely related to Wicksell's verbal description:

There is a certain rate of interest on loans which is neutral in respect to commodity prices, and tends neither to raise nor to lower them.

Wicksell (1936, p. 102)

In characterizing the natural rate of interest, we focus on a medium-run concept of price stability that abstracts from the effects of short-run price and output fluctuations. In this respect, our definition differs from that advanced recently by Woodford (2000), who defines the Wicksellian natural rate of interest to be the real rate that yields period-by-period price stability. Woodford's characterization of the natural rate does not correspond to the intercept term in a monetary policy rule that contains independent responses to output and inflation, but instead fully describes the optimal setting of policy for a particular objective function (Cf. Woodford (2001)). In fact, existing estimates based on this definition abstract entirely from lower frequency components of $r^{*}$ and potential output by using detrended data (Cf. Rotemberg and Woodford (1997), Neiss and Nelson (2001)). Importantly, these estimates are very sensitive to the structural assumptions of the particular model, and, as a result, yield policy prescriptions that are unlikely to be robust to model uncertainty (Cf. Levin, Wieland and Williams (1999)). In contrast, our goal is to provide a robust method of identifying lower-frequency movements in $r^{*}$ that can be included in the kind of "simple" policy rules that have been shown to perform well in a wide variety of models (Cf. Levin, Wieland and Williams (2001)).

Because we define the natural rate of interest in relation to the deviation of output from potential, estimation of $r^{*}$ also entails estimation of potential output. ${ }^{4}$ Moreover, owing to the theoretical linkage between $r^{*}$ and the trend growth rate, we are interested in estimating

\footnotetext{
${ }^{3}$ For example, if we follow Solow (1956) and assume that the saving rate is constant, then the real interest rate will also be positively related to the rate of growth and negatively to the saving rate (the latter presumably negatively related to the rate of time preference). Specifically, $r=\alpha \frac{\delta+n+q}{s}-\delta$, where $s$ is the saving rate out of output and $\delta$ is the rate of depreciation.

${ }^{4}$ An alternative would be to specify a reduced-form relationship between the change in the rate of inflation
} 
both the level of potential output and its trend growth rate. We apply the Kalman filter to these unobserved low frequency variables, modeling the cyclical dynamics of output and inflation using a restricted VAR model that imposes relatively little structure on short-run dynamics. Because the innovation variances to $r^{*}$ and the trend growth rate are small, we use Stock and Watson's (1998) median-unbiased estimates of these coefficients and apply maximum likelihood to estimate the remaining model parameters.

Time variation in $r^{*}$ and in particular its real-time mismeasurement is potentially important for the conduct and performance of monetary policy. In a recent paper, however, Rudebusch (2001) finds that transitory shocks to $r^{*}$ have only modest implications for the conduct of monetary policy. In this paper, we reexamine this issue in the context of the estimated highly persistent movements in $r^{*}$ over history and come to the conclusion that there are relatively large stabilization losses associated with $r^{*}$ mismeasurement, and that these losses can be mitigated by timely updating of $r^{*}$ estimates.

The remainder of the paper is organized as follows. The next section describes the empirical framework used for estimating the natural rate of interest, potential output, and trend growth. Section three describes the estimation methodology and reports estimation results. Section four examines the robustness of these results to changes in the estimates of potential output and trend growth. Section five investigates the effects of $r^{*}$ mismeasurement on the performance of monetary policy. Section six concludes.

\section{An Empirical Framework for Measuring the Natural Rate}

As noted, we apply the Kalman filter to estimate the natural rate of interest, the level of potential output, and its trend growth rate. One alternative would be to use a univariate time-series method to estimate $r^{*}$. However, such an approach is problematic because it does not control for the sustained periods of rising and declining inflation in the United States during the past several decades. In particular, given that the natural rate of interest and the deviation of the real interest rate from $r^{*}$; however, this approach is likely to yield very weak identification of $r^{*}$. An altogether different approach is to use forward rates implied by the term structure and a measure of inflation expectations to estimate low frequency movements in the natural rate of interest (Cf. Brayton, Mauskopf, Reifschneider, Tinsley and Williams (1997), Kozicki and Tinsley (2001)). In recent work, Bomfim (2001) uses forward rates from Treasury inflation-indexed bonds to estimate $r^{*}$ over the three years that they have been issued. One difficulty with this general approach is that one must account for time-variation in the term premium evident in the data. 
is related to medium-run inflation stability, such univariate methods are likely to underestimate $r^{*}$ during the 1960s and 1970s when inflation was rising, and overestimate it during the disinflationary episodes of the early 1980s and the 1990s..$^{5}$ For this reason, we estimate the natural rate within a model consisting of inflation, output, and real interest rates.

Econometric identification of $r^{*}$ is achieved by specifying a simple reduced-form equation relating the output gap (the percent deviation of real GDP from potential output) to its own lags and a moving average of the lagged real funds rate gap (the difference between the real funds rate and $r^{*}$ ), and a serially uncorrelated error. ${ }^{6}$ Specifically, we assume that

$$
\tilde{y}_{t}=A_{y}(L) \tilde{y}_{t-1}+A_{r}(L)\left(r_{t-1}-r_{t-1}^{*}\right)+\epsilon_{1 t},
$$

where $\tilde{y}_{t}=100 *\left(y_{t}-y_{t}^{*}\right)$ denotes the output gap, $y_{t}$ is the logarithm of real GDP, $y_{t}^{*}$ is the logarithm of unobserved potential GDP, $r_{t}$ is the ex ante real federal funds rate, and $r_{t}^{*}$ is the unobserved natural rate of interest. (See the Appendix for details on data construction.) The serially uncorrelated error and the lags of the output gap control for transitory shocks and short-run dynamics, while highly persistent shifts in this relationship between the output gap and the real funds rate are ascribed to changes in $r^{*}$. Hence, we require $\sum a_{y}$ to be less than unity in order to identify changes in $r^{*}$ with low frequency shifts in the output gap-real rate relationship

Inflation, $\pi_{t}$, is measured by the annualized growth rate of the price index for personal consumption expenditures excluding food and energy - referred to hereafter as core PCE inflation - and is assumed to be determined by its own lags, the output gap, relative prices, $x_{t}$, and a serially uncorrelated error,

$$
\pi_{t}=B_{\pi}(L) \pi_{t-1}+B_{y}(L) \tilde{y}_{t-1}+B_{x}(L) x_{t}+\epsilon_{2 t} .
$$

\footnotetext{
${ }^{5}$ For example, the trend component of the real funds rate based on the Hodrick-Prescott filter rises sharply during the period of the Volcker disinflation. This estimate of the natural rate of interest would inappropriately ascribe a large portion of the disinflationary policy action to a shift in the natural rate.

${ }^{6}$ The basic specification of output gap dynamics is very similar to that in Rudebusch and Svensson (1999), except that they assume a constant value of $r^{*}$. An alternative specification is to include the real bond rate as in Fuhrer (1997), instead of the real fed funds rate. This approach introduces two additional complications. First, in order to compute the ex ante real long rate, one needs to measure multi-year inflation expectations, which are arguably more prone to measurement error than near-term inflation expectations associated with the short-term interest rate. Second, in so far as we are seeking to estimate a natural rate useful for a monetary policy rule, the term premium, itself a potentially time-varying process, would also need to be estimated. We leave this to further research.
} 
The relative price variables include measures of core import price and crude oil import price inflation, both measured as deviations from core PCE inflation. Potential GDP is defined as the level of GDP that is consistent with unchanged inflation in the absence of relative price shocks, $x_{t}$, and the serially uncorrelated disturbance, $\epsilon_{2 t}$. Equations (2) and (3) constitute the measurement equations of our state-space model.

As noted, economic theory implies that the trend growth rate is one determinant of $r^{*}$. Hence, we specify

$$
r_{t}^{*}=c g_{t}+z_{t}
$$

where $g_{t}$ is our estimate of trend growth and $z_{t}$ captures other determinants of $r^{*}$, such as households' rate of time preference. We assume that $z$ follows an autoregressive process,

$$
z_{t}=D_{z}(L) z_{t-1}+\epsilon_{3 t}
$$

where $\epsilon_{3 t}$ is assumed to be a serially uncorrelated innovation. In principle, $z$ may be stationary or nonstationary; in the following we consider two specific cases: (1) $z$ is described by a stationary $\operatorname{AR}(2)$ process, and (2) $z$ follows a random walk.

As noted, there is evidence for time variation in the trend growth rate, with a slowdown occuring during the 1970s and a pickup during the late 1990s. We allow for shocks to both the level of potential output - the I(1) component - and its trend growth rate - the $\mathrm{I}(2)$ component. For reasons of parsimony, we specify a simple random walk model for both components. Specifically, potential output is assumed to evolve according to

$$
\begin{aligned}
y_{t}^{*} & =y_{t-1}^{*}+g_{t-1}+\epsilon_{4 t}, \\
g_{t} & =g_{t-1}+\epsilon_{5 t},
\end{aligned}
$$

where $\epsilon_{4 t}$ and $\epsilon_{5 t}$ are serially uncorrelated and mutually contemporaneously uncorrelated with the innovation to $z, \epsilon_{3 t}$. Assuming the standard deviation of the disturbance to the growth rate component of potential output is positive, potential output is a second-order integrated process. ${ }^{7}$ If potential output is $\mathrm{I}(2)$ and $c \neq 0$, then $r^{*}$ is integrated of order one, even if the $z$ process is stationary. Equations (4)-(7) constitute the transition equations of our state-space model.

\footnotetext{
${ }^{7}$ The hypothesis that log real GDP is I(2) is typically rejected by an ADF test. However, as Stock and Watson (1998) point out, when the disturbance to the growth rate component has small variance, such a test statistic has a high false-rejection rate.
} 
Several authors have used variants of the model (2)-(7) to obtain trend-cycle decompositions of GDP, but none incorporate interest rates in their models. Watson (1986) considers a model with constant trend growth $g$ and an AR specification for the output gap. Clark (1987) extends Watson's model and allows for time variation in trend growth. Kuttner (1994) explores the relationship between the cyclical component of GDP and inflation by including a dynamic inflation equation. ${ }^{8}$ Roberts (2001) decomposes output growth into growth in hours and labor productivity growth, and allows for time variation in the trend growth rates of both of these series. As noted, none of these contributions include the effect of interest rates and, as a result, they do not address the issue of time variation in the natural rate of interest.

\section{Estimation}

We estimate several variants of the model described above on quarterly U.S. data over the period 1961:1 to 2000:4. Details on the data used are given in the Appendix. We allow the lag lengths in the output gap and inflation equations, equations (2) and (3), respectively, to be determined by the data. Specifically, we include two lags each of the output gap and the real rate gap in the output gap equation. The finding that the output gap is well characterized by an $\operatorname{AR}(2)$ is consistent with the studies using unobserved components models cited above. We impose the restriction that the coefficients on the two lags of the real rate gap are the same, which is not rejected by the data for any of our specifications.

We include eight lags of inflation in the inflation equation and impose the restriction, not rejected by the data, that the coefficients sum to unity. For reasons of parsimony, we restrict the coefficients on lags 2 to 4 of inflation to be equal, and the same for lags 5 to 8 (Cf. Gordon (1998), Brayton, Roberts and Williams (1999)). Including only the first lag of the output gap in this equation proved sufficient. Finally, the relative price vector, $x_{t}$, consists of contemporaneous core import price inflation, and the first lag of oil import price inflation, both measured relative to core PCE inflation.

\footnotetext{
${ }^{8}$ In a related paper, Laubach (2001) identifies the natural rate of unemployment using a model of inflation dynamics.
} 


\subsection{Estimation Methodology}

In principle, the model can be estimated by maximum likelihood using the Kalman filter. However, the contributions from variation in trend growth and the natural rate of interest to overall variability in the data are relatively small. As a result, the maximum likelihood estimates of the standard deviations of the innovations to these processes, $\sigma_{3}$ and $\sigma_{5}$, are likely to be biased towards zero owing to the so-called "pile-up problem" discussed by Stock (1994). Indeed, the maximum likelihood estimates of both of these parameters were zero. We therefore use Stock and Watson's (1998) median-unbiased estimator to obtain estimates of the ratio $\lambda_{g} \equiv \frac{\sigma_{5}}{\sigma_{4}}$, and, in cases where $z$ is nonstationary, $\lambda_{z} \equiv \frac{\sigma_{3}}{\sigma_{1}} \frac{a_{r}}{\sqrt{2}} .{ }^{9}$ We impose these ratios when estimating the remaining model parameters (including $\sigma_{1}$ and $\sigma_{4}$ ) by maximum likelihood. Because the pile-up problem does not arise for stationary unobserved processes, in cases where $z$ is stationary, we estimate the standard deviation of its innovation, $\sigma_{3}$, by maximum likelihood simultaneously with the other model parameters.

We proceed in three steps. In the first step, we generate a preliminary estimate of potential output, which we use as an input in estimating $\lambda_{g}$. We follow Kuttner (1994) and apply the Kalman filter to estimate potential output, omitting the real rate gap term from equation (2) and assuming that the trend growth rate, $g$, is constant. We compute the exponential Wald statistic of Andrews and Ploberger (1994) for a structural break with unknown break date on this preliminary estimate of potential output. We then use Stock and Watson's results to convert the exponential Wald statistic into an estimate $\hat{\lambda}_{g}$. Applying Stock and Watson's method to the preliminary estimate of potential GDP, instead of directly to the GDP data, has the advantage that it is consistent with their assumption that all shocks have a permanent effect on the level of the series under consideration. Correspondingly, when applying the method to our preliminary estimate of potential GDP we do not correct the data for serial correlation in the level shocks, as Stock and Watson suggest.

If the unobserved component of the natural rate of interest, $z$, is assumed to be station-

\footnotetext{
${ }^{9}$ This ratio is based on the assumption that the coefficients on the two lags of the real rate gap are the same. Substituting (4) into (2), the latter can be written as

$$
\tilde{y}_{t}=A_{y}(L) \tilde{y}_{t-1}+\frac{a_{r}}{2}\left(r_{t-1}+r_{t-2}-c\left(g_{t-1}+g_{t-2}\right)\right)-\frac{a_{r}}{2}\left(z_{t-1}+z_{t-2}\right)+\epsilon_{1 t}
$$

The ratio $\lambda_{z}$ based on the test statistic for an intercept shift at unknown date in this equation is thus the ratio of $a_{r} \sigma_{3} / \sqrt{2}$ to $\sigma_{1}$.
} 
ary, we proceed directly to the third and final step; otherwise, in the second step, we impose the estimated value of $\lambda_{g}$ from the previous step and follow a similar process to generate an estimate of $\lambda_{z}$. We again estimate the five model equations, imposing $\sigma_{5}=\hat{\lambda}_{g} \sigma_{4}$. We now include the real interest rate gap in the output gap equation, but assume that $z$ is constant; that is, we assume $r_{t}^{*}=c g_{t}+$ constant. Using this specification, we compute the exponential Wald statistic for an intercept shift in the output gap equation at an unknown break date, and use Stock and Watson's results to obtain an estimate $\hat{\lambda}_{z}$.

In the third and final step, we impose the estimated values of $\lambda_{g}$ from the first step and $\lambda_{z}$ from the second step (assuming $z$ is nonstationary), and estimate the remaining model parameters by maximum likelihood. ${ }^{10}$ As noted, if $z$ is assumed to be stationary, we include $\sigma_{3}$ in the parameters to be estimated by maximum likelihood. We compute estimated confidence intervals and corresponding standard errors for the estimates of the states using Hamilton's (1986) Monte Carlo procedure, which accounts for both filter and parameter uncertainty. ${ }^{11}$

\subsection{Estimation Results}

The first-stage estimation of potential output indicates that the trend growth rate exhibits only a relatively modest amount of variation over time. The first line in Table 1 reports the value of the exponential Wald statistic testing for an intercept shift in the first difference of potential GDP. This value of 1.51 is just below the 10 percent critical value of 1.55 given in Andrews and Ploberger (1994, Table 1, page 1399). Using Stock and Watson's median-unbiased estimator, this relatively weak evidence of a change in the growth rate of potential GDP translates into an estimate of $\lambda_{g}$ of about 0.04, shown in the second column of the table. When multiplied by our third-stage estimate of $\sigma_{4}$ reported below, the implied standard deviation of trend growth changes is estimated to be about 0.1 percentage

\footnotetext{
${ }^{10}$ Estimates of the conditional expectation and covariance matrix of the initial state are computed using the GLS method discussed in Harvey (1989, p. 122). Because these estimates are functions of the model parameters, for certain parameter values the covariance matrix may be ill conditioned. The conditional expectation of the initial values of $y^{*}$ and $g$ is then computed by fitting a segmented trend through log real GDP, with $z$ initialized at zero, and the covariance matrix is set to 0.2 times the identity matrix. During the Monte Carlo simulations for computing the standard errors, this procedure is modified as discussed in Laubach (2001, p. 222).

${ }^{11}$ Note that these estimated confidence intervals hold the imposed values of $\lambda_{g}$ and $\lambda_{z}$ fixed but take into account the uncertainty regarding $\sigma_{1}, \sigma_{2}, \sigma_{4}$, and, thus, implicitly $\sigma_{3}$ and $\sigma_{5}$.
} 
Table 1: First- and Second-stage Estimation Results

\begin{tabular}{|c|c|ccc|}
\hline \multirow{2}{*}{ Variable } & \multirow{2}{*}{$\begin{array}{c}\text { Exponential } \\
\text { Wald }\end{array}$} & \multicolumn{3}{|c|}{ Median-unbiased Estimate of $\lambda$} \\
\cline { 3 - 5 } & Statistic & Point & 90 \% Confidence Interval \\
\cline { 3 - 5 } & 1.51 & .039 & .000 & .103 \\
\hline Trend growth $(g)$ & 4.28 & .071 & .015 & .117 \\
Natural rate $(z)$ & &
\end{tabular}

point (expressed at an annual rate), a figure almost identical to Stock and Watson's (1998) comparable estimate. The 90 percent confidence intervals for the estimate of $\lambda_{g}$, computed by Monte Carlo simulations, are given in the final two columns of the table. ${ }^{12}$ Note that the lower end of the 90 percent confidence interval for the estimate of $\lambda_{g}$ includes zero, the case in which the trend growth rate is constant and potential output is integrated of order one.

The results from the second-stage estimation indicate the presence of persistent time variation in $z$, the component of $r^{*}$ not related to the trend growth rate. As seen in the second line of Table 1, the value of the exponential Wald statistic testing for an intercept shift in the output gap equation is 4.28 , which is significant at the 1 percent level. The implied median-unbiased estimate of $\lambda_{z}$ is 0.07 . In cases where we assume that the process $z$ is nonstationary - and in particular, described by a random walk - we impose this estimated value of $\lambda_{z}$ in the third and final estimation stage.

Turning to the final-stage estimation, we begin by assuming that $z$ follows a stationary $\mathrm{AR}(2)$ process. The results from maximum likelihood estimation of this model are reported in the first column of Table 2. The estimated coefficients $d_{z}$ are consistent with $z$ being stationary. The estimated sum of coefficients on the lagged output gap in the output gap equation is below unity (and the unit sum hypothesis is rejected at conventional levels), consistent with the identification assumptions described in Section 2. Finally, the real rate gap enters the output gap equation with the correct sign and is significant at the one percent level.

The natural rate of interest is estimated to vary one-for-one with changes in the trend

\footnotetext{
${ }^{12}$ To compute this confidence interval, we use parameter estimates based on the second-stage model with a time-varying trend growth and a constant natural rate of interest to construct 10,000 simulated series of $\left\{y_{t}^{*}, g_{t}\right\}$. For each pair of simulated series we compute the exponential Wald statistic for an intercept shift in the first difference of $y_{t}^{*}$.
} 
Table 2: Parameter Estimates

\begin{tabular}{|l|cccc|}
\hline \multirow{2}{*}{ Parameter } & Stationary & \multicolumn{3}{c|}{ Random Walk Model for $z$} \\
\cline { 2 - 5 } & $z \sim \operatorname{AR}(2)$ & Baseline & Low $\lambda_{z}$ & High $\lambda_{z}$ \\
\hline$\lambda_{z}$ & .045 & .071 & .015 & .117 \\
& $(.24)$ & & & \\
\hline$\sum a_{y}$ & .924 & .943 & .942 & .944 \\
$a_{r}$ & -.117 & -.104 & -.091 & -.114 \\
& $(3.20)$ & $(3.67)$ & $(3.66)$ & $(3.63)$ \\
$b_{y}$ & .060 & .040 & .059 & .030 \\
& $(1.95)$ & $(1.57)$ & $(1.84)$ & $(1.37)$ \\
$c$ & .970 & 1.062 & 1.001 & 1.008 \\
& $(3.89)$ & & & \\
$\sum d_{z}$ & .965 & 1 & 1 & 1 \\
$\sigma_{1}(\tilde{y})$ & .263 & .364 & .406 & .327 \\
$\sigma_{2}(\pi)$ & .719 & .725 & .721 & .728 \\
$\sigma_{3}(z)$ & .142 & .352 & .095 & .475 \\
$\sigma_{4}\left(y^{*}\right)$ & .655 & .627 & .610 & .639 \\
$\sigma_{5}(g)$ & .102 & .098 & .095 & .100 \\
\hline$\sigma_{r^{*}}=\sqrt{c^{2} \sigma_{5}^{2}+\sigma_{3}^{2}}$ & .173 & .367 & .134 & .485 \\
Log Likelihood & -360.5 & -362.9 & -362.2 & -363.0 \\
\hline Standard Error $($ ave. $)$ & & & & \\
$r^{*}$ & 2.58 & 1.98 & 1.09 & 2.38 \\
$g$ & .42 & .48 & .42 & .53 \\
$y^{*}$ & 2.33 & 3.25 & 1.97 & 4.32 \\
\hline Notes: $t$ statistics in parentheses. $\sigma_{5}$ & is expressed at annual rate. \\
Standard errors are sample averages for smoothed estimates of states. \\
\hline
\end{tabular}


growth rate of output, and this result is robust to changes in the process for $z$. For the case of stationary $z, c$ is estimated to be .97 , with a standard error of .25 . The second column of Table 2 reports the estimation results for the case where $z$ is modeled as a random walk and $\lambda_{z}$ is estimated using the median-unbiased estimator. The results are very similar to those where $z$ is assumed to follow an $\operatorname{AR}(2)$. In particular, the estimate of $c$ is also near unity. However, owing to the existence of two nonstationary processes determining $r^{*}-$ $g$ and $z$ - this latter estimate must be treated with caution owing to the potential for spurious correlation (Cf. Granger and Newbold (1974)). For this reason, in cases where $z$ is nonstationary, inference based on the standard errors is invalid and we therefore do not report t-statistics for the estimates of the coefficient $c$.

The final two columns of Table 2 indicate the estimation results when we impose values for $\lambda_{z}$ corresponding to the lower and upper limits of the 90 percent confidence intervals, instead of the median-unbiased point estimate. Again, the coefficient $c$ relating $r^{*}$ to the trend growth rate is near unity, consistent with the previous results. Except for the standard deviations of the innovations, the parameter estimates are little affected by the choice of $\lambda_{z}$. The more variable the $z$ process and therefore $r^{*}$, the lower the variance of the serially uncorrelated innovations to the output gap equation. Note that, based on the log likelihood values, the data are not able to discern between the alternative specifications shown in the table.

The smoothed (two-sided) estimates of the unobserved processes implied by our model estimates are shown in Figure 1. The $r^{*}$ estimates in the model in which $z$ follows a stationary $\operatorname{AR}(2)$ (indicated by the dashed line) exhibit far larger short-duration swings than those where $z$ is assumed to follow a random walk (the solid line). For this reason, for the remainder of the paper, we focus on the random walk specification, which appears to correspond more closely to our middle- and low-frequency characterization of the natural rate of interest. We refer to the specification given in the second column as the "baseline model;" the restriction to the random walk specification for $z$ is not rejected by the data at the 5 percent level. This estimate of $r^{*}$ peaks at about $4-1 / 2$ percent in the mid-1960s, reaches a minimum of $1-1 / 4$ percent in the early 1990s, and ends the sample period at just above its sample average of 3 percent.

The estimates of the trend growth rate and the output gap are very similar across the four estimates. As shown in the middle panel of the figure, the estimated trend growth 
Figure 1: Smoothed Estimates of Unobserved States

Natural Rate of Interest $\left(r^{*}\right)$
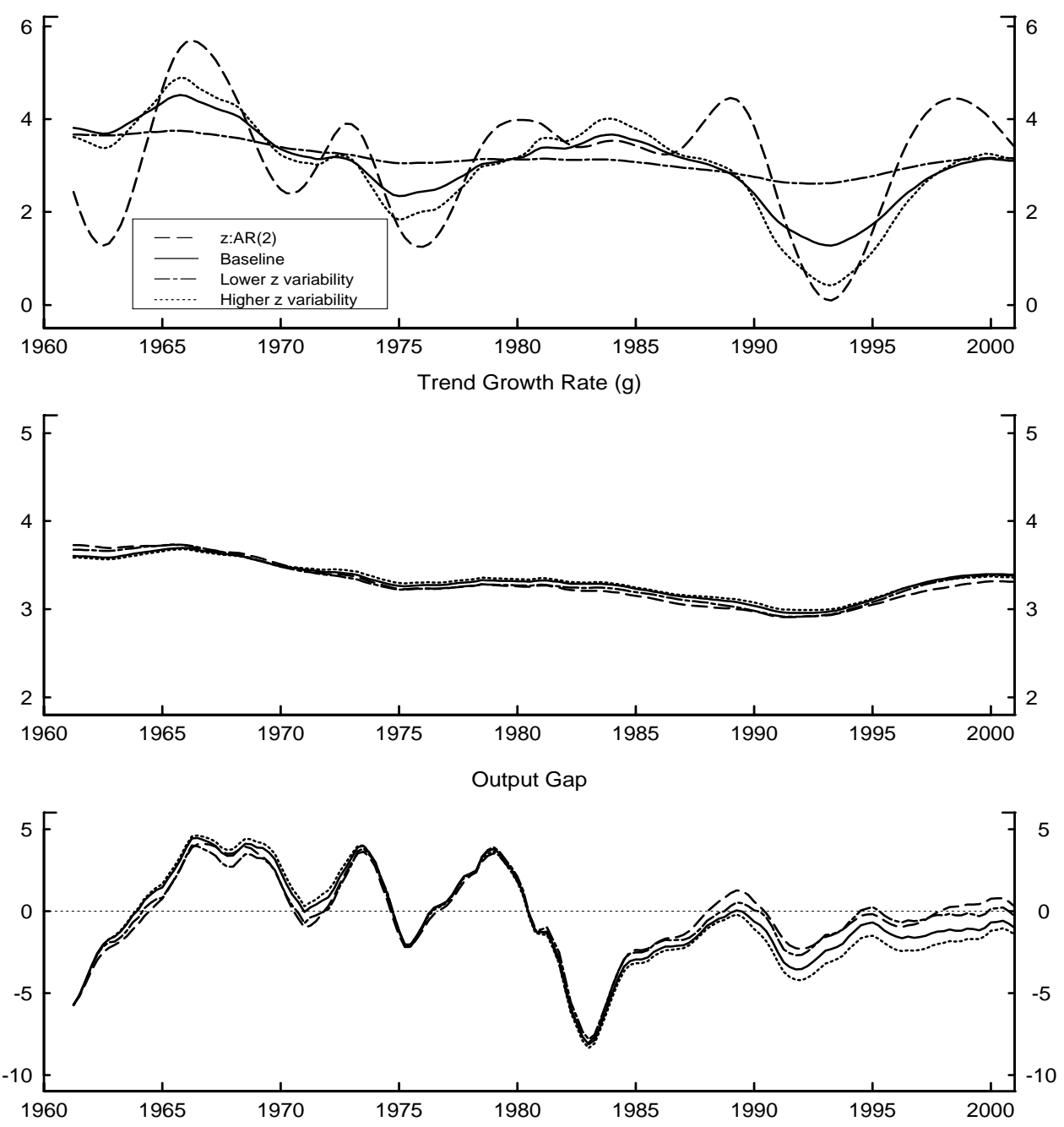

rate peaks in the mid-1960s at about 3-3/4 percent, and then declines through the 1970s and 1980s. From its low of about 3 percent in the early 1990s, the trend growth rate increases by about one-half percentage point by the end of the sample. The broad outline of the output gap estimate, shown in the lower panel, corresponds closely to the estimates of Clark (1987) and Kuttner (1994) over the parts of the sample that are covered by their estimates, although Kuttner's estimate is more volatile than either ours or Clark's.

The standard errors of the estimates of the unobserved states, shown at the bottom of Table 2, are relatively large, as is typical for Kalman filter estimates. As a result, changes in the natural rate of interest and the trend growth rate of output are not measured with 
much precision. Across the specifications reported in the table, the average standard error of $r^{*}$ ranges from 1 to $2-1 / 2$ percentage points, that for the trend growth rate is about $1 / 2$ percentage point, and that for the level of potential output from 2 to $4-1 / 2$ percentage points.

\section{Robustness Analysis}

We now extend the preceding robustness analysis to include changes in estimates of potential output and the trend growth rate. Our definition of the natural rate as the real interest rate at which real GDP equals potential, once the effects of transitory shocks have dissipated, implies that our natural rate estimates are sensitive to our estimate of potential GDP. We first consider alternative estimates based on the uncertainty surrounding our estimate of $\lambda_{g}$; we then examine the effects of augmenting the model with a labor market indicator to assist in the decomposition of GDP into trend and cyclical components.

If the trend growth rate is assumed to be constant, then the estimate of the natural rate of interest is significantly less variable than in the baseline estimates. The second column of Table 3, labeled "Low $\lambda_{g}$ ", reports results from estimating the baseline model under the assumption that $\lambda_{g}=0$, the lower end of its 90 percent confidence interval. For comparison, the first column of the table repeats the baseline results from Table 2. With a constant trend growth rate, $c$ is not identified. The resulting estimate of $\lambda_{z}$ is 0.026 , well below that in the baseline specification. Evidently, when modeled as a pure random walk, $r^{*}$ is poorly identified. As a result, a significantly greater portion of output gap variability is ascribed to serially uncorrelated shocks and less to permanent shocks. This is illustrated graphically in the upper panel of Figure 2. Interestingly, the output gap estimates, shown in the lower panel of the figure, differ relatively little between the constant growth rate and the baseline estimates.

Increasing the variability of the trend growth rate, however, has relatively modest effects on the estimated parameters and the estimates of $r^{*}$. The third column of the table reports

the results when $\lambda_{g}$ takes the value 0.103 , corresponding to the upper end of the 90 percent confidence interval. In this case, the estimate of $\lambda_{z}$ is .060, slightly lower than the baseline estimate. Except for the greater variability of the trend growth rate itself, the parameter estimates do not differ substantially from the baseline estimates. In particular, the estimate 
Table 3: Parameter Estimates under Different Potential Output Assumptions

\begin{tabular}{|l|cccc|}
\hline Parameter & Baseline & Low $\lambda_{g}$ & High $\lambda_{g}$ & Hours \\
\hline$\lambda_{g}$ & .039 & .000 & .103 & .046 \\
$\lambda_{z}$ & .071 & .026 & .060 & .039 \\
\hline$\sum a_{y}$ & .943 & .944 & .946 & .927 \\
$a_{r}$ & -.104 & -.087 & -.124 & -.076 \\
& $(3.67)$ & $(3.66)$ & $(3.60)$ & $(3.09)$ \\
$b_{y}$ & .040 & .055 & .031 & .096 \\
& $(1.57)$ & $(1.88)$ & $(1.28)$ & $(3.02)$ \\
$c$ & 1.062 & - & .995 & .886 \\
\hline$\sigma_{1}$ & .364 & .397 & .257 & .497 \\
$\sigma_{2}$ & .725 & .722 & .729 & .714 \\
$\sigma_{3}$ & .352 & .168 & .175 & .359 \\
$\sigma_{4}$ & .627 & .622 & .662 & .547 \\
$\sigma_{5}$ & .098 & .000 & .273 & .101 \\
$\sigma_{6}$ & - & - & - & .245 \\
\hline$\sigma_{r^{*}}=\sqrt{c^{2} \sigma_{5}^{2}+\sigma_{3}^{2}}$ & .367 & .168 & .323 & .370 \\
Log Likelihood & -362.9 & -362.3 & -363.5 & $-466.5^{1}$ \\
\hline Standard Error (ave.) & \multicolumn{5}{|c}{} \\
$r^{*}$ & 1.98 & 1.28 & 1.63 & 2.65 \\
$g$ & .48 & .24 & .74 & .46 \\
$y^{*}$ & 3.25 & 2.18 & 3.48 & .59 \\
\hline Notes: $t$ statistics in parentheses. $\sigma_{4}$ is expressed at annual rate. \\
Standard errors are sample averages for smoothed estimates of states. \\
1. Log likelihhod for model augmented with equation for employee hours \\
is not comparable to others. & & & \\
\hline & & & & \\
\hline
\end{tabular}


Figure 2: Sensitivity of Estimates to Assumptions Regarding Potential Output Natural Rate of Interest $\left(r^{*}\right)$
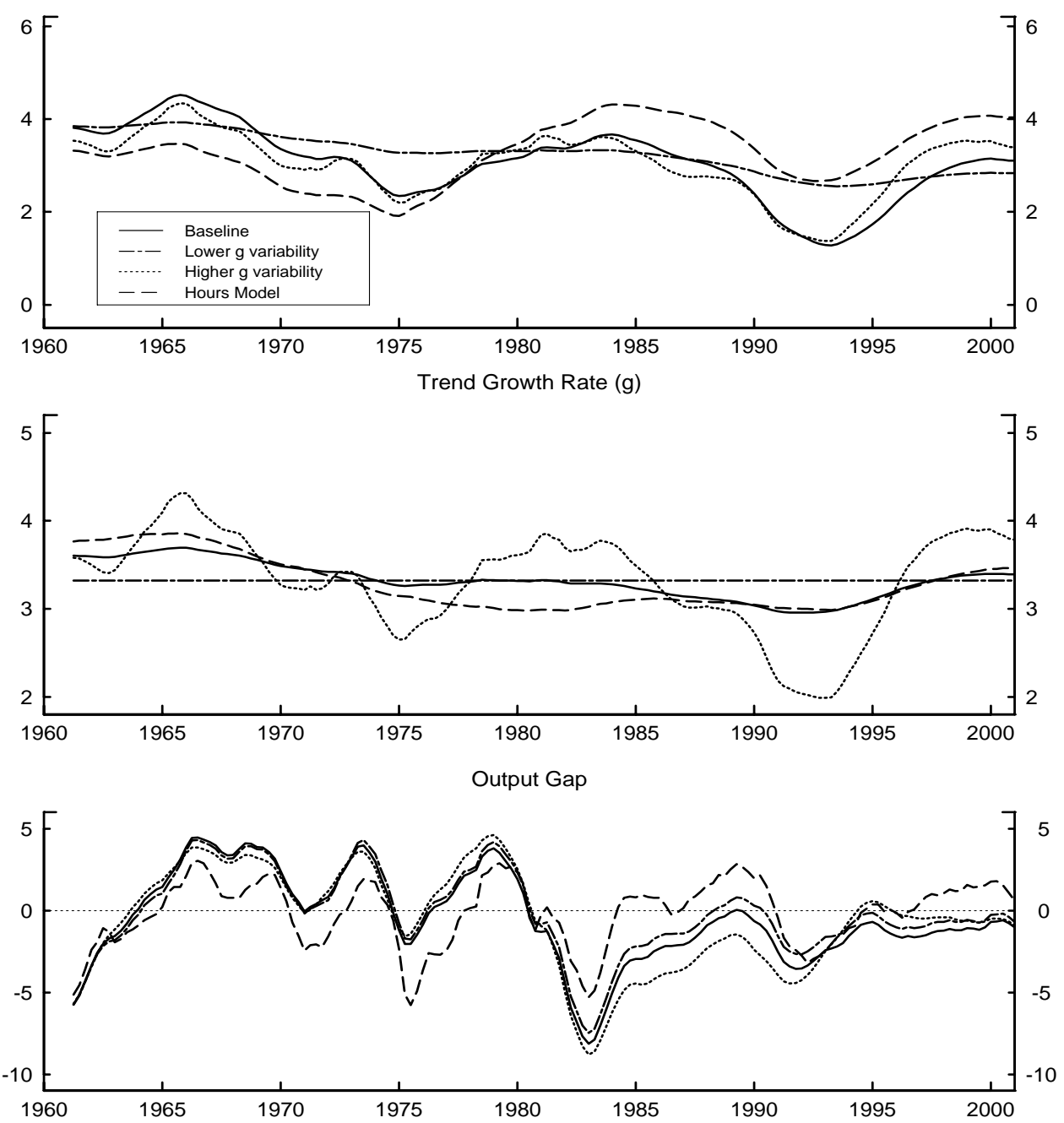

of $c$ is again nearly unity. As seen in the figure, although the estimated trend growth rate is much more variable (shown by the dotted line in the middle panel), the resulting estimates of $r^{*}$ differ relatively little from the baseline estimates.

\subsection{Incorporating Information on Employment Hours}

Our second alternative specification for potential GDP is based on the notion that employment hours, as well as inflation, contain information about the cyclical state of the economy. Specifically, we follow Roberts (2001) and introduce the equation

$$
\tilde{h}_{t}=f_{1} \tilde{y}_{t}+f_{2} \tilde{y}_{t-1}+f_{3} \tilde{h}_{t-1}+\epsilon_{6 t}
$$


into the model, where $\tilde{h}_{t}$ denotes percent deviations of private nonfarm employee hours $h_{t}$ from a trend $h_{t}^{*}$. We compute $\tilde{h}_{t}$ as the deviation of hours from a simple log-linear time trend (Cf. Rotemberg and Woodford (1996)). ${ }^{13}$

Estimation results for this specification are shown in the final column of Table 3, labeled "Hours." The resulting estimate of $\lambda_{g}$ is a little larger than the baseline value, but the estimate of $\lambda_{z}$ is considerably lower than the baseline value. However, because the variance of the serially uncorrelated innovation to the output gap equation rises while that of the level shock to potential GDP falls, the variability of both the trend growth rate and the natural rate of interest are nearly the same as in the baseline specification. The estimate of $c$ is about 0.9 , just a bit below the other estimates.

The uncertainty around the output gap estimate shown at the bottom of Table 3 is less than one fifth of that in the baseline specification. The high degree of precision regarding the estimate of the level of potential output results from the close fit of equation (8), combined with the absence of any unobserved states in the estimation of trend hours. A problematic aspect of the estimation results for the model augmented with hours is that it appears to be in conflict with evidence of low frequency changes in the growth rate of labor supply (Cf. Roberts (2001)). For this reason, the precision of the estimates may be spurious.

The close identification of the output gap with deviations of hours from a time trend implies a different view of history compared to the baseline model where the output gap is identified by the inflation equation alone. As shown in Figure 2, in the model augmented with the hours equation (the dashed line), both the output gap and $r^{*}$ are estimated to have been below their baseline counterparts in the first half of the sample, and above them in the second half. In particular, during the late 1990s, a period when core PCE inflation was declining, the baseline estimate indicates that output was below potential and therefore exerting downward pressure on inflation, while the model augmented with the hours equation indicates output was above potential and therefore boosting inflation. Evidently, the estimates of potential output in the baseline specification include the effects of omitted variables that influence inflation but are not captured by movements in hours.

\footnotetext{
${ }^{13}$ In principle, $h_{t}^{*}$ could be specified as an I(2) process analogous to $y_{t}^{*}$. However, tests for an intercept shift in the raw hours data over our sample show no evidence for such a shift. Moreover, when attempting to construct a preliminary estimate of trend hours by estimating a trend-cycle decomposition based on a constant drift in trend hours, trend hours are estimated to be a simple time trend. These results differ from those of Roberts (2001) who normalizes hours by population and finds this series to be I(2).
} 


\subsection{Overall Robustness of Estimates}

Table 4: Properties of Unobserved Variables

\begin{tabular}{|l|ccccccc|}
\hline & $z \sim \mathrm{AR}(2)$ & Baseline & Low $\lambda_{z}$ & High $\lambda_{z}$ & Low $\lambda_{g}$ & High $\lambda_{g}$ & Hours \\
\hline Natural Rate of Interest & & & & & & & \\
Minimum & .10 & 1.28 & 2.62 & .42 & 2.55 & 1.38 & 1.91 \\
& $(92: 4)$ & $(92: 4)$ & $(92: 1)$ & $(92: 4)$ & $(93: 1)$ & $(92: 3)$ & $(74: 3)$ \\
Maximum & 5.70 & 4.52 & 3.75 & 4.90 & 3.93 & 4.34 & 4.31 \\
& $(65: 4)$ & $(65: 2)$ & $(65: 2)$ & $(65: 2)$ & $(65: 2)$ & $(65: 2)$ & $(83: 4)$ \\
Ending Value & 3.40 & 3.10 & 3.16 & 3.16 & 2.84 & 3.39 & 4.04 \\
Trend Growth Rate & & & & & & & \\
Minimum & 2.91 & 2.96 & 2.91 & 2.99 & 3.32 & 1.99 & 2.98 \\
Maximum & $(90: 4)$ & $(91: 3)$ & $(91: 2)$ & $(91: 3)$ & - & $(92: 2)$ & $(80: 1)$ \\
Ending Value & 3.73 & 3.70 & 3.73 & 3.68 & 3.32 & 4.32 & 3.86 \\
Output Gap & $(65: 1)$ & $(65: 2)$ & $(65: 2)$ & $(65: 2)$ & - & $(65: 2)$ & $(65: 2)$ \\
Minimum & 3.31 & 3.39 & 3.38 & 3.36 & 3.32 & 3.79 & 3.46 \\
& & & & & & & \\
Maximum & -8.04 & -8.14 & -7.82 & -8.36 & -7.48 & -8.80 & -5.77 \\
Ending Value & $(82: 3)$ & $(82: 3)$ & $(82: 3)$ & $(82: 3)$ & $(82: 3)$ & $(82: 3)$ & $(75: 1)$ \\
& 4.11 & 4.45 & 3.99 & 4.61 & 4.30 & 4.60 & 3.03 \\
& $(66: 2)$ & $(66: 1)$ & $(65: 4)$ & $(66: 1)$ & $(73: 1)$ & $(78: 3)$ & $(66: 1)$ \\
& .27 & -1.03 & -.30 & -1.42 & -1.69 & -.92 & .61 \\
\hline
\end{tabular}

Despite the sizeable uncertainty around most of our estimates of the natural rate of interest, the trend growth rate, and potential output, our point estimates of these processes are qualitatively similar across the seven model variants described above. This is illustrated in Table 4, which shows the minimum, maximum, and ending values of the smoothed estimates of the natural rate of interest, the trend growth rate, and the output gap. In the six cases that exclude the hours equation, $r^{*}$ peaked in 1965 and hit its sample low in 1992 or 1993. In the model augmented with the hours equation, $r^{*}$ hits its low in 1973 and peaks in 1983. All estimates show the trend growth rate peaking in 1965 and the low point occurring in the early 1990s (the augmented model has two nearly identical minima, in 1980 and in the early 1990s). The estimates of the output gap are generally similar, with the peaks occurring in the late 1960s and the mid- and late-1970s; the minimum occurs in the 
Figure 3: Estimates of the Stance of Monetary Policy

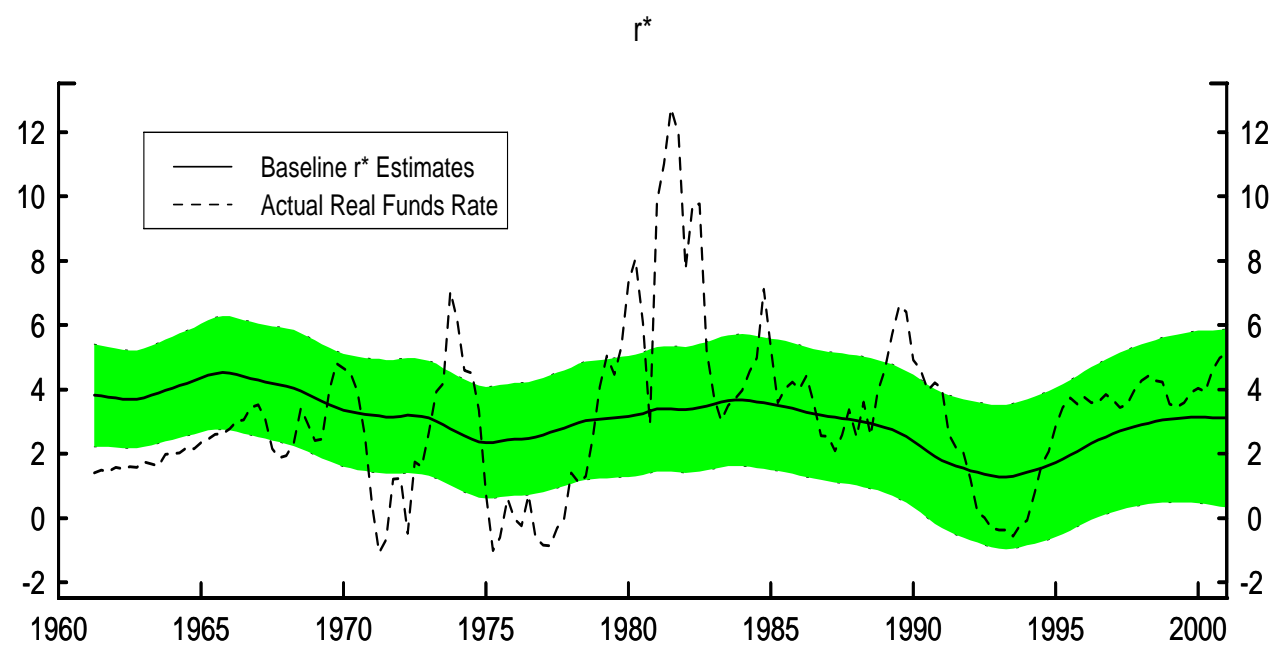

early 1980s (with the augmented model showing an equally large negative gap in 1975).

\section{Monetary Policy and a Time-varying Natural Interest Rate}

Allowing for time variation in the natural rate of interest can significantly change one's view of the stance of monetary policy during historical episodes in which $r^{*}$ strayed from its historical average. Figure 3 shows the baseline $r^{*}$ estimates (the solid lines), along with the corresponding actual values of the real fed funds rate (the dashed lines). The shaded region in the figure shows the 70 percent confidence intervals for the $r^{*}$ estimates. The estimated decline in the natural rate during the early 1990s suggests that the stance of policy during the early 1990s may not have been as expansionary as one would believe based on a constant value of $r^{*}$. Similarly, monetary policy appears much easier in the late 1960s, relative to the assumption of a constant natural rate of interest, when one accounts for the boost to $r^{*}$ resulting from relatively strong trend growth during that period.

$R^{*}$ mismeasurement interferes with the achievement of both inflation and output stabilization goals. The achievement of a long-run inflation rate goal requires that estimates of $r^{*}$ converge to the true value in expectation. Let policy be described by the interest rate feedback rule,

$$
i_{t}=\pi_{t}^{e}+\hat{r}_{t}^{*}+\alpha_{\pi}\left(\pi_{t}-\pi^{*}\right)+\alpha_{y} \tilde{y}_{t}
$$

where $\hat{r}_{t}^{*}$ is the policymaker's estimate of the natural rate of interest, $\pi^{e}$ is expected inflation, 
Figure 4: Real-time Estimates of the Natural Rate of Interest

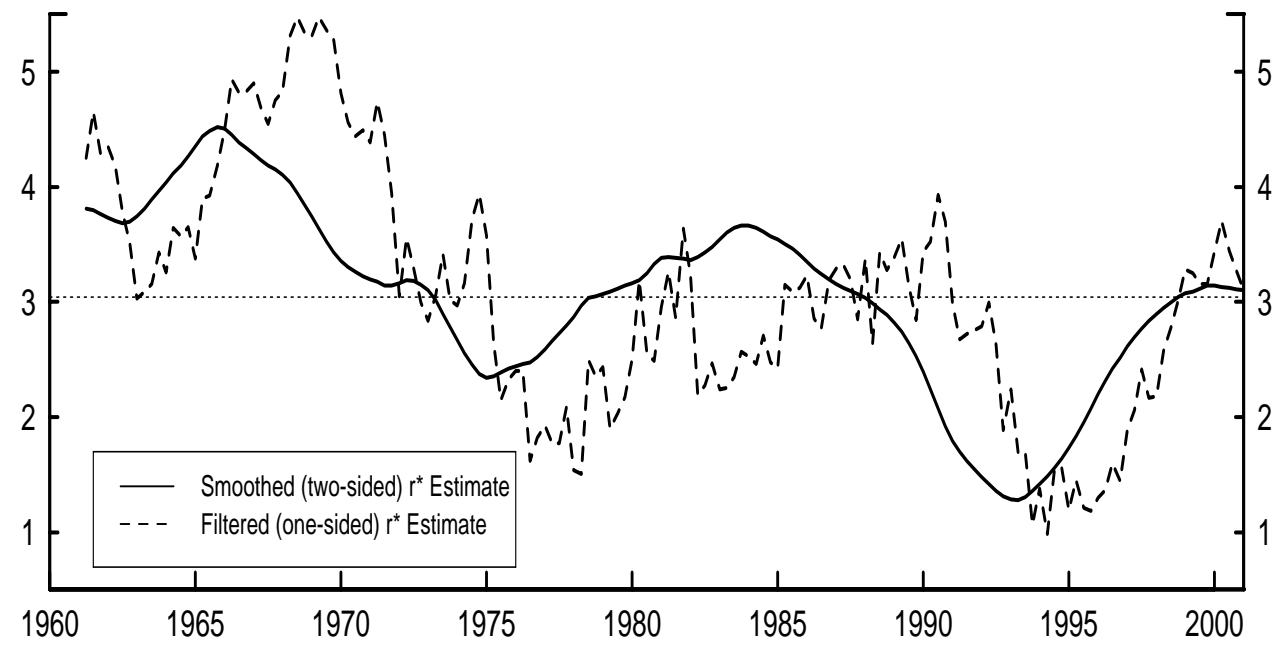

and $\pi^{*}$ is the (fixed) long-run inflation target. Absent shocks, if the policymaker's estimate converges to $\hat{r}^{*}$, then the inflation rate converges to $\pi^{*}+\frac{1}{\alpha_{\pi}}\left(r^{*}-\hat{r}^{*}\right)$. Hence, if $r^{*}$ is subject to permanent shifts, then for the inflation rate to stabilize at the target level, the policymaker's estimate must converge in expectation to the true value.

Mismeasurement of $r^{*}$ also implies a deterioration in short-run macroeconomic stabilization. In the absence of mismeasurement, a time-varying natural rate of interest has no implications for the performance resulting from a policy rule of the form of equation (9) beyond greater variability of real interest rates. But, $r^{*}$ mismeasurement introduces an additional disturbance to the system, the magnitude of which depends on the variance of the $r^{*}$ innovations and the persistence of which depends on the Kalman filter gain used in updating estimates of $r^{*}$.

Comparing one-sided and two-sided estimates of $r^{*}$ provides a measure of the likely magnitude and persistence of $r^{*}$ mismeasurement. Figure 4 shows the baseline one-sided filter estimates (the dashed line) and the two-sided smoothed estimates (the solid line) of the natural rate of interest. For comparison, the sample mean of the smoothed estimate - about 3 percent - is shown by the horizontal dashed line. The one-sided filter estimates correspond to a "real-time" estimate of $r^{*}$ in that past data are used in estimating the state. ${ }^{14}$ Taking the smoothed estimate as truth, the standard deviation of the measurement error using the one-sided filter is about 0.9 percentage point over the sample; nearly 10 percent of

\footnotetext{
${ }^{14}$ The full sample is used to estimate the model parameters, however, so the analogy is not exact.
} 
Table 5: Effects of $r^{*}$ Mismeasurement under the Taylor Rule

\begin{tabular}{|c|c|c|c|c|c|}
\hline \multirow[b]{2}{*}{ Policymaker's Estimate of $r^{*}$} & \multicolumn{3}{|c|}{ Standard Deviation } & \multirow{2}{*}{$\begin{array}{c}\text { Loss } \\
\mathcal{L}\end{array}$} & \multirow{2}{*}{$\begin{array}{c}\text { \% Increas } \\
\text { in Loss }\end{array}$} \\
\hline & $\tilde{y}$ & $\pi$ & $\Delta i$ & & \\
\hline True value $\left(\hat{r}_{t}^{*}=r_{t}^{*}\right)$ & 1.1 & 1.4 & .7 & 3.5 & - \\
\hline One-sided KF estimate & 1.5 & 1.4 & 1.0 & 4.7 & 34 \\
\hline Constant $\left(\hat{r}^{*}=3.0\right)$ & 1.6 & 1.6 & .7 & 5.4 & 53 \\
\hline
\end{tabular}

the existing measurement error is eliminated each quarter. For comparison, the sample standard deviation of the smoothed $r^{*}$ estimate is 0.8 percentage point, and the first-order autocorrelation is 1.00 .

We use simulations of the estimated baseline model to assess the effects of $r^{*}$ mismeasurement owing to time variation in the natural rate of interest. For these simulations, we assume the true values of potential output and $r^{*}$ are given by the respective two-sided Kalman filter estimates of our baseline model. We assume that policy is set according to the Taylor Rule (that is, $\alpha_{\pi}=\alpha_{y}=.5$ ), and that the true value for potential output is observed. We conduct three simulations. In one, the policymaker knows the true value of $r^{*}$ each period. In the second, the policymaker uses the one-sided Kalman filter estimate, which corresponds to a "real-time" estimate of $r^{*}$. In the third, the policymaker assumes $r^{*}$ is a constant 3 percent, equal to the mean value of the two-sided estimate. Note that we are restricting the scope of mismeasurement to that resulting from the time variation in the natural rate; we assume that the policymaker correctly knows the sample mean of $r^{*}$. Each simulation extends over 1961-2000; to mitigate the effects of initial and terminal conditions, the results are computed for 1964-1997 only.

We assume the policymaker's objective is to minimize the weighted sum of the variances of the output gap, the inflation rate, and the change in the nominal federal funds rate. Specifically, we follow Rudebusch and Svensson (1999) and Rudebusch (2001) and specify the loss function:

$$
\mathcal{L}=\operatorname{Var}(\pi)+\operatorname{Var}(\tilde{y})+\frac{1}{2} \operatorname{Var}(\Delta i),
$$

where $\operatorname{Var}(x)$ signifies the unconditional variance of variable $x$.

Model simulations indicate that mismeasurement of the natural rate of interest leads to a significant deterioration in output stabilization, but has relatively modest effects on inflation stabilization. The first three columns of Table 5 report the simulated standard de- 
viations of the output gap, the inflation rate, and the change in the nominal funds rate. The fourth column reports the value of the loss given by equation (10); the final column shows the percent increase in the loss relative to the case of no $r^{*}$ mismeasurement. Assuming $r^{*}$ is constant increases the loss by over 50 percent relative to the case of no mismeasurement. Using the one-sided Kalman filter estimate significantly improves stabilization performance. $^{15}$

\section{Conclusion}

In this paper, we have jointly estimated the natural rate of interest, potential output, and the trend growth rate using the Kalman filter. We find that the natural rate of interest shows significant variation over the past forty years in the United States. These results are robust to changes in specification. Variation in the trend growth rate is an important determinant of changes in the natural rate, as predicted by theory. We show that time variation of the natural rate has important implications for the design and implementation of monetary policy. Adjustment to changes in the natural rate is crucial for the achievement of long-run inflation and short-run stabilization goals. The periods of the late 1960s and the early 1990s provide particularly acute examples where recognition of the time-varying nature of the natural rate has a profound influence on the ability to stabilize inflation and output.

This paper has focused on the postwar U.S. economy. The analytical apparatus can easily be adapted to other countries and an interesting issue is whether factors can be identified that affect the long-run natural rate across countries. In addition, this approach can be extended to estimate the underlying natural rates of other financial variables, such as the equity premium or the real exchange rate.

\footnotetext{
${ }^{15}$ Rudebusch (2001) claims relatively modest effects of $r^{*}$ mismeasurement based on model simulations of transitory shocks to $r^{*}$ around a known mean. That study implicitly assumes policymakers update their $r^{*}$ estimates, reducing the magnitude and persistence of mismeasurement relative to a constant $r^{*}$ assumption. In addition, the coefficients of the policy feedback rule are reoptimized when $r^{*}$ mismeasurement is introduced, reducing the implied effects on macroeconomic stabilization.
} 


\section{Appendix}

This appendix describes the data used in this study. The variable $y$ refers to the $\log$ of real chain-weighted GDP in billions of chained 1996 dollars. The federal funds rate is the annualized nominal funds rate, with the quarterly figure computed as the average of the monthly values. Because the federal funds rate frequently fell below the discount rate prior to 1965, we use the Federal Reserve Bank of New York's discount rate prior to 1965.

Our measure of inflation is the annualized quarterly growth rate of the price index for personal consumption expenditures excluding food and energy, referred to as core PCE inflation. To construct a series for the ex ante real federal funds rate, we compute the expectation of average inflation over the four quarters ahead from a univariate $\operatorname{AR}(3)$ of inflation estimated over the 40 quarters prior to the date at which expectations are being formed. To compute these expectations for the early part of our sample, we need to use inflation data prior to 1959:2, the start of the core PCE inflation series. For these dates we splice overall PCE inflation to core PCE inflation. Our results do not change perceptibly if inflation expectations are proxied by a four-quarter moving average of inflation instead of the forecast from the univariate AR.

The relative price variables included in the inflation equation are core import price and crude oil import price inflation. The core import price series is the implicit deflator

for imports of nonpetroleum goods. From 1968 on, this series also excludes the prices of computers and semiconductors. Finally, the hours data are total hours of employees and self-employed persons in the private nonfarm business sector. 


\section{References}

Andrews, Donald and Werner Ploberger, "Optimal Tests When a Nuisance Parameter Is Present Only Under the Alternative," Econometrica, 1994, 62, 1383-1414.

Bomfim, Antulio, "The Equilibrium Fed Funds Rate and the Indicator Properties of Term-Structure Spreads," Economic Inquiry, October 1997, 35 (4), 830-46.

_ , "Measuring Equilibrium Real Interest Rates: What can we learn from yields on indexed bonds?," July 2001. manuscript, Board of Governors of the Federal Reserve System.

Brayton, Flint, Eileen Mauskopf, David Reifschneider, Peter Tinsley, and John Williams, "The Role of Expectations in the FRB/US Macroeconomic Model," Federal Reserve Bulletin, 1997, 83 (4), 227-245.

, John Roberts, and John C. Williams, "What's Happened to the Phillips Curve?," September 1999. FEDS Paper No. 1999-49, Board of Governors of the Federal Reserve System.

Clark, Peter, "The Cyclical Component of U.S. Economic Activity," Quarterly Journal of Economics, November 1987, 102, 797-814.

Fuhrer, Jeffrey C., "Inflation/Output Variance Trade-Offs and Optimal Monetary Policy," Journal of Money, Credit and Banking, May 1997, 29 (2), 214-34.

Gordon, Robert J., "Foundations of the Goldilocks Economy: Supply Shocks and the Time-Varying NAIRU," Brookings Papers on Economic Activity, 1998, pp. 297-333.

Granger, Clive and Paul Newbold, "Spurious Regressions in Econometrics," Journal of Econometrics, 1974, 2, 111-120.

Hamilton, James, "A Standard Error for the Estimated State Vector of a State-Space Model," Journal of Econometrics, 1986, 33, 387-397.

Harvey, Andrew C., Forecasting, Structural Time Series Models and the Kalman Filter, Cambridge, UK: Cambridge University Press, 1989. 
Kozicki, Sharon and P.A. Tinsley, "Shifting Endpoints in the Term Structure of Interest Rates," Journal of Monetary Economics, June 2001, 47 (3), 613-652.

Kuttner, Kenneth, "Estimating Potential Output as a Latent Variable," Journal of Business and Economic Statistics, July 1994, 12 (3), 361-368.

Laubach, Thomas, "Measuring the NAIRU: Evidence form Seven Economies," Review of Economics and Statistics, May 2001, 83 (2), 218-231.

Levin, Andrew, Volker Wieland, and John C. Williams, "Robustness of Simple Monetary Policy Rules under Model Uncertainty," in John B. Taylor, ed., Monetary Policy Rules, Chicago: University of Chicago Press, 1999, pp. 263-299.

, _ _ and _ _ , "The Performance of Forecast-Based Monetary Policy Rules under Model Uncertainty," 2001. Board of Governors of the Federal Reserve System, FEDS working paper 2001-39.

Maddison, Angus, Monitoring the World Economy, 1820-1992, Paris: Organization for Economic Co-operation and Development, 1995.

Neiss, Katharine and Edward Nelson, "The Real Interest Rate Gap as an Inflation Indicator," April 2001. Bank of England working paper No. 130.

Oliner, Stephen D. and Daniel E. Sichel, "The Resurgence of Growth in the Late 1990s: Is Information Technology the Story?," Journal of Economic Perspectives, Fall 2000, 14 (4), 3-22.

Orphanides, Athanasios and Volker Wieland, "Price Stability and Monetary Policy Effectiveness when Nominal Interest Rates are Bounded at Zero," 1998. FEDS Working Paper 1998-35, Board of Governors of the Federal Reserve System.

Reifschneider, David and John C. Williams, "Three Lessons for Monetary Policy in a Low Inflation Era," Journal of Money, Credit and Banking, November 2000, 32 (4), 936-966.

Roberts, John M., "Estimates of the Producivity Trend Using Time-Varying Parameter Techniques," Contributions to Macroeconomics, 2001, 1 (1), 1-27. 
Rotemberg, Julio J. and Michael Woodford, "Real Business-Cycle Models and the Forecastable Movements in Output, Hours, and Consumption," American Economic Review, March 1996, 86, 71-89.

and _ _ "An Optimization-Based Econometric Framework for the Evaluation of Monetary Policy," in "NBER Macroeconomics Annual 1997," Cambridge, MA: The MIT Press, 1997, pp. 297-346.

Rudebusch, Glenn D., "Is the Fed Too Timid? Monetary Policy in an Uncertain World," Review of Economics and Statistics, 2001, 83 (2), 203-17.

and Lars E. O. Svensson, "Policy Rules for Inflation Targeting," in John B. Taylor, ed., Monetary Policy Rules, Chicago: University of Chicago Press, 1999, pp. 203-253.

Solow, Robert M., "A Contribution to the Theory of Economic Growth," Quarterly Journal of Economics, February 1956, 70, 65-94.

Stock, James, "Unit Roots, Structural Breaks and Trends," in R. Engle and D. McFadden, eds., Handbook of Econometrics, Vol. 4, Amsterdam: Elsevier, 1994, pp. 2739-2841.

and Mark Watson, "Median Unbiased Estimation of Coefficient Variance in a TimeVarying Parameter Model," Journal of the American Statistical Association, March 1998, 93, 349-358.

Taylor, John B., "Discretion versus Policy Rules in Practice," Carnegie Rochester Conference Series on Public Policy, 1993, 39, 195-214.

and John C. Williams, "Forecasting with Rational Expectations Models," December 1993. manuscript, Stanford University.

Watson, Mark, "Univariate Detrending Methods with Stochastic Trends," Journal of Monetary Economics, 1986, 18, 49-75.

Wicksell, Knut, Interest and Prices, London: Macmillan, 1936. translation of 1898 edition by R.F. Kahn.

Woodford, Michael, "A Neo-Wicksellian Framework for the Analysis of Monetary Policy," September 2000. manuscript, Princeton University. 
__ "The Taylor Rule and Optimal Monetary Policy," American Economic Association Papers and Proceedings, May 2001, 91 (2), 232-237. 